\title{
How work spills over into the relationship: Self-control matters
}

\author{
GERDIENTJE DANNER-VLAARDINGERBROEK, ESTHER S. KLUWER, \\ ELIANNE F. VAN STEENBERGEN, AND TANJA VAN DER LIPPE
}

\author{
Utrecht University, The Netherlands
}

\begin{abstract}
This research investigated how and for whom experiences of the workday spill over into relationship functioning at home. Two correlational studies and one experimental study were conducted among Dutch dual-earners with children. Moderated mediation analyses showed that work demands spill over into relationship behavior through the depletion of temporary self-regulatory resources and subsequently a decrease in psychological availability for the partner. Whether work demands spill over into relationship behavior was dependent on dispositional self-control in that evidence for negative spillover was only found for individuals low in dispositional self-control. The experimental study showed that the induction of gratitude for the partner after the workday helped individuals low in dispositional control to prevent negative spillover into the partner relationship.
\end{abstract}

Dual-earners with young children are challenged by managing the combined responsibilities of being a partner, a parent, and an employee (Bianchi, Robinson, \& Milkie, 2006). It is well established that stress and strain from work can have detrimental effects on the marital relationship (e.g., Eby, Casper, Lockwood, Bordeaux, \& Brinley, 2005; Hughes \& Galinsky, 1994). Experiences during work can cause feelings of frustration or exhaustion that can spill over into the

At the time of the research, Gerdientje DannerVlaardingerbroek worked at the Department of Social and Organizational Psychology, Utrecht University, Utrecht, Netherlands; Esther S. Kluwer, Department of Social, Health, and Organizational Psychology, Utrecht University, Utrecht, Netherlands; Elianne F. van Steenbergen, Department of Social, Health, and Organizational Psychology, Utrecht University, Utrecht, Netherlands; Tanja van der Lippe, Department of Sociology, Utrecht University, Utrecht, Netherlands

This research was supported by a Utrecht University High Potential grant awarded to Esther Kluwer and Tanja van der Lippe.

Correspondence should be addressed to Esther S. Kluwer, Utrecht University, Department of Social, Health, and Organizational Psychology, Heidelberglaan 1, P.O. Box 80.410, 3508 TC Utrecht, Netherlands, e-mail: E.s.kluwer@uu.nl. home domain and affect the way employees interact with their family members after work (e.g., Danner-Vlaardingerbroek, Kluwer, van Steenbergen, \& van der Lippe, 2013; Story \& Repetti, 2006). This work-family spillover is defined as the within-person transmission of feelings or behavior and subsequent strain from the work domain into the family domain (Bakker, Demerouti, \& Burke, 2009). The increasing number of dual-earner families in Western society, and also in The Netherlands where the current research was conducted (Merens, Hartgers, \& van den Brakel, 2012), stresses the importance of studying the effects of work experiences on close relationships. In the literature, considerable attention has been paid to studying the consequences of work-family spillover, including relationship functioning (for an overview, see Eby et al., 2005). Although associations between work factors and relationship functioning have been frequently demonstrated, the underlying psychological mechanism of work-family spillover has received little attention so far. In addition, it remains unknown whether some individuals are more prone to spillover than 
others. Thus, there are still important gaps in the literature about the spillover process from work experiences to relationship functioning. Knowledge about these mechanisms can provide valuable insight into possibilities to prevent negative spillover and reduce its detrimental consequences for close relationships. The central aim of this study is therefore to investigate how and for whom work demands are related to relationship functioning at home.

A central theoretical framework in the work-family literature is the spillover model, which acknowledges the importance of the spillover of psychological states from one role into the other (e.g., Greenhaus \& Beutell, 1985; Piotrkowsky, 1979). This model posits that negative experiences at work may leave the individual in a certain psychological state (e.g., feeling frustrated, depressed, or ineffective), which may spill over into the home role, contributing to negative marital interactions, dissatisfaction, or worse role performance at home (e.g., Rogers \& May, 2003). The few studies that looked at the spillover process in more detail primarily evaluated mood as an explanation for the spillover process. For example, Song, Foo, and Uy (2008) showed that work moods were associated with home moods, and Story and Repetti (2006) showed that work demands were associated with negative marital interactions through negative mood. However, these previous studies did not explain how a negative mood-induced by stressors at work-is related to negative partner interactions. Moreover, there may be additional mechanisms besides negative mood that account for spillover.

In this study, we examine how a demanding workday is associated with an individual's psychological state and subsequently with the ability to positively interact with the partner. In the following sections, we argue that work demands are related to relationship behavior through the depletion of resources and the subsequent decrease of psychological availability for the partner. In addition, we argue that some individuals are more prone to work-family spillover than others and that this spillover process depends on individual differences in dispositional self-control.

\section{Work demands and the depletion of resources}

During demanding workdays, physical, emotional, and cognitive activities use and therefore temporarily deplete self-regulatory resources. Activities that require the employee to regulate emotions, thoughts, and behaviors are more effortful than other-more automatic-processes because they require higher order cognitive processes (Miyake et al., 2000) and thus consume specific self-regulatory resources (Finkel \& Campbell, 2001). As conceptualized by the self-regulatory strength model, self-regulation can be viewed as a strength that is limited and depletable due to situational factors such as willpower exertion, stress, or exhaustion (Baumeister \& Heatherton, 1996). Work demands that require self-regulatory resources are negative social interactions at work (Repetti, 1993). For example, dealing with an angry colleague results in an unpleasant emotional state, and effortful self-regulation processes are needed to terminate this state (Baumeister, Bratslavsky, Finkenauer, \& Vohs, 2001; Green, Sedikides, Saltzberg, Wood, \& Forzano, 2010). Also, high work pressure can drain the employee's self-regulatory resources (Bakker \& Geurts, 2004). For example, switching rapidly between different tasks is known to involve effortful cognitive control processes, reducing one's self-regulatory resources in stock (Monsell, 2003). Finally, working individuals often have to inhibit their impulses to react to distractions when trying to concentrate on a task; this inhibition is effortful and can temporarily reduce self-regulatory resources (Miyake et al., 2000). In sum, we hypothesize that work demands result in the depletion of self-regulatory resources at the end of the workday.

\section{Depletion and psychological availability}

To maintain close relationships, partners generally engage in activities to repair, sustain, and continue their relationship (Stafford \& Canary, 1991). For example, they might listen and pay attention to their partner's worries, they might try to remain calm when their partners are angry, or they might postpone their own need 
fulfillment in favor of their partner's need fulfillment. According to interdependence theory (Kelley \& Thibaut, 1978; Rusbult \& van Lange, 1996), these maintenance behaviors are often costly because partners have to consider what is good for the relationship and act upon these considerations, which is more effortful than relying on automatic impulses that are usually tuned in favor of the self. Maintenance behaviors thus require self-regulation and use higher order cognitive processes (Yovetich \& Rusbult, 1994).

Danner-Vlaardingerbroek and colleagues (2013) captured these psychological resources in a measurable concept called "psychological availability." Psychological availability is defined as one's ability and motivation to direct psychological resources at the partner, that is, being interpersonally present for the partner and having the mental capacity to actively direct attention toward the partner. An individual who is psychologically available for the partner has enough cognitive space to rapidly weigh a sensitive response to the partner and has the capacity to sense the partner's needs. Because work demands can deplete the amount of self-regulatory resources, we expect that this diminishes the resources that are needed for partner-directed considerations. In other words, we expect that the depletion of self-regulatory resources by work is associated with a decrease in psychological availability for the partner.

One particular type of relationship behavior that has the function to maintain a good relationship is accommodation. Accommodation is defined as reacting constructively rather than destructively to a partner's potentially destructive behavior (Rusbult, Verette, Whitney, Slovik, \& Lipkus, 1991). As noted previously, to forego or inhibit an automatic and self-interested destructive reaction toward the partner is effortful and requires self-regulation. Indeed, research has shown that positive relationship behavior or accommodation is less likely to occur when individuals have fewer self-regulatory resources available (Baumeister, Vohs, \& Tice, 2007; Finkel \& Campbell, 2001). Therefore, we hypothesize that the depletion of self-regulatory resources will be associated with a diminished psychological availability for the partner and subsequently with a decrease in accommodative tendencies.

\section{Individual differences in dispositional self-control}

Not all working individuals will be equally prone to work-to-relationship spillover. In addition to temporal levels of self-regulatory resources that can fluctuate depending on the situation, individuals differ in their general or dispositional capacity to regulate the self (Baumeister, Gailliot, DeWall, \& Oaten, 2006; Tangney, Baumeister, \& Boone, 2004). Dispositional self-control or trait self-control is conceptualized as a relatively stable personality trait entailing the degree to which individuals are able to control and inhibit impulses and alter their behavior across time and across situations (Finkel \& Campbell, 2001). Dispositional self-control is related to many positive, desirable outcomes such as good grades and work performance, lower risk of impulse control problems like binge eating or alcohol abuse, good psychological adjustment, and healthy interpersonal relationships (Tangney et al., 2004). More specifically, the more dispositional self-control both partners have together, the better their relationship quality (Vohs, Finkenauer, \& Baumeister, 2011). In addition, Finkel and Campbell (2001) found that after conducting a task in which self-regulatory resources were depleted, individuals low in dispositional self-control showed a larger decrease in accommodative tendencies compared to persons high in dispositional self-control. This suggests that the behavior of individuals high in dispositional self-control is less affected by variations in self-regulatory resources than the behavior of individuals low in dispositional self-control. In other words, we expect that individuals with high self-control are better able to show positive partner behaviors despite being depleted than individuals with low self-control. Therefore, we hypothesize stronger negative spillover effects among individuals low in dispositional self-control than among those high in dispositional self-control. 


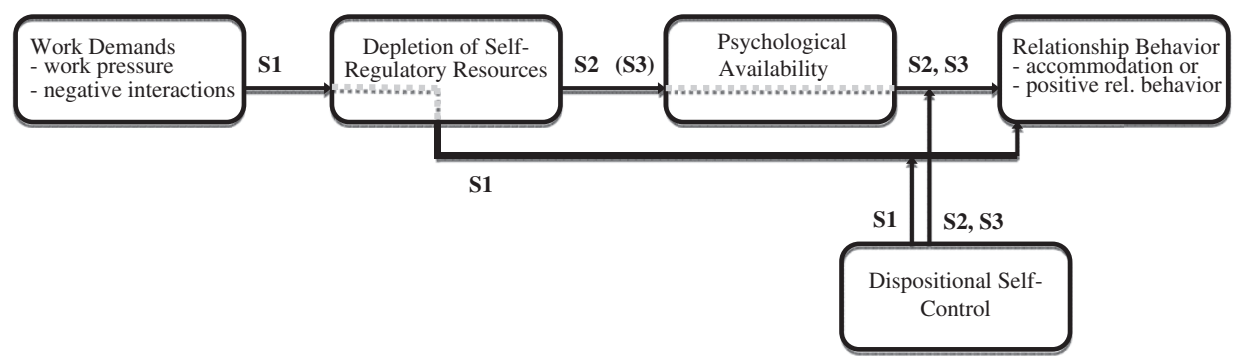

Figure 1. Conceptual model. For each path, it is indicated in which study (and corresponding hypothesis) the direct and indirect associations are examined.

\section{Research overview}

To gain insight in how and for whom work experiences spill over into relationship functioning, we conducted three studies using both correlational and experimental methods. The first study aimed to examine the mediating role of self-regulatory resources in the association between work experiences and marital behavior as well as the moderating role of dispositional self-control. Using a cross-sectional survey, we tested whether work demands were related to diminished accommodation through the depletion of self-regulatory resources at the end of a workday for individuals low in dispositional self-control, but to a lesser degree for individuals high in dispositional self-control (Hypothesis 1; see Figure 1). Study 2 aimed to further specify the spillover process by examining the mediating role of psychological availability in the association between the depletion of self-regulatory resources after work and marital behavior. In a cross-sectional survey, we assessed whether the negative link between the depletion of self-regulatory resources at the end of a workday and accommodative behavior in the evening was mediated by a decrease in psychological availability for the partner after the workday. Again, we tested whether this mediation effect was stronger for individuals low in dispositional self-control compared to individuals high in dispositional self-control (Hypothesis 2; see Figure 1). In Study 3, we aimed to strengthen the findings of the first two studies by using a quasi-experimental design. We examined whether increasing psychological availability for the partner after the workday, while controlling for self-regulatory resources, would enhance positive relationship behavior compared to a control group. Once again, we examined whether this effect was stronger for individuals low in dispositional self-control compared to individuals high in dispositional self-control (Hypothesis 3; see Figure 1).

\section{Study 1}

The primary goal of Study 1 was to examine whether work demands were associated with partner relationship behavior through the depletion of self-regulatory resources and whether this mediation effect differed depending on individuals' dispositional self-control (i.e., a moderated mediation effect). Based on our theoretical framework, we hypothesized that work demands were negatively related to accommodative tendencies via the depletion of self-regulatory resources. We expected this mediation effect to be stronger among individuals low in dispositional self-control than among individuals high in dispositional self-control (Hypothesis 1).

\section{Method}

\section{Procedure and participants}

Data for this study were derived from a larger study that was conducted to study the relations among work functioning, depletion, recovery, and family functioning. The study was conducted among a sample of 83 Dutch dual-earners using a snowball technique. Participation criteria were that participants worked a minimum of $24 \mathrm{hr}$ per week, lived 
together with their partner, and had at least one child living at home. Three research assistants distributed e-mails to acquaintances, including an invitation asking them to participate and to forward the invitation to other dual-earners who might be interested. The e-mail explained that the data from the study would be treated anonymously and confidentially. The research assistants distributed questionnaires to the participants after agreement.

Participants completed the questionnaire in the evening on a Thursday or Sunday of a week in which they had worked. Participants received a small gift (i.e., a magazine) after returning the questionnaire. In the original study, this design was conducted to obtain variance in the amount of recovery from work across respondents. Testing the hypotheses of the current study, however, required a homogeneous group of respondents with recent work experiences without variation in recovery. Therefore, we selected the participants that had worked on the same day that they filled in the questionnaire, resulting in a sample of 47 dual-earners. Thus, although participants had different jobs, different work hours, or came home at different times, all selected participants in this study had worked on the day of participation. The majority of the selected participants (31 out of 47) worked for 4 consecutive days prior to participation.

The majority of the participants were male (79\%); $92 \%$ of the sample was married, and the remaining $8 \%$ lived together. Participants were on average 45.83 years old $(S D=8.38$, range $=30-60$ years old). Males worked on average $36.91 \mathrm{hr}$ per week $(S D=4.50)$, and females worked on average $30.87 \mathrm{hr}$ per week $(S D=7.47)$. The majority was higher educated (63\%). Participants had on average 2.54 children $(S D=1.03)$ aged between 0 and 29 years, with an average age of the youngest child being 10.07 years $(S D=7.05)$. The high percentage of men in this sample is most likely due to the work hour criterion in the original study, namely, working more than $24 \mathrm{hr}$ a week. In The Netherlands, many women of dual-earner families with school-aged children have part-time jobs of $24 \mathrm{hr}$ or less. In 2011, for example, women worked $24.0 \mathrm{hr}$ a week on average compared to $40.6 \mathrm{hr}$ for men (Merens et al., 2012).

To investigate possible selection effects, we compared the selected group that worked on the day of participation $(N=47)$ with the excluded group that did not work on the day of participation $(N=36)$ on background variables (i.e., age, age of the youngest child, number of children, and weekly work hours) and on the study variables (i.e., work demands, depletion of self-regulatory resources, dispositional self-control, and accommodation; see the next section for measurement). Weekly work hours differed significantly between the groups, but when we tested separately for men and women, there was no significant difference for work hours. We found no significant differences between the samples on any of the other variables, except for depletion of self-regulatory resources. As expected, the selected group who worked on the day of participation reported more depletion $(M=3.37, S D=1.11)$ than the excluded group who did not work on the day of participation $(M=2.69, S D=.97)$, $t(80)=-2.94, p<.01$. Thus, individuals in the selected group had indeed recovered less from their work experiences than individuals who did not work on the day of participation.

\section{Measures}

Work demands of the preceding workweek were measured by four items about work pressure (Williams \& Alliger, 1994) and two items about negative social interactions (Repetti, 1993). Example items are: "During work the last week, I had to put high effort in my work tasks" and "During work the last week, I had an unpleasant argument with a coworker" (Cronbach's $\alpha=.62$ ). Reducing the number of items did not increase the scale reliability. The low $\alpha$ should therefore be considered a limitation as it can reduce the statistical power of the study. Depletion of self-regulatory resources at the end of the workday was assessed with the 10-item Concurrent Depletion Scale (Finkel \& Campbell, 2001). Example items are: "At this moment I feel tired," "At this moment I feel frustrated," or "At this moment I feel busy" (Cronbach's $\alpha=.85$ ). A higher score on this scale represented more depletion 
Table 1. Means, standard deviations, and correlation coefficients of the study variables (Study 1)

\begin{tabular}{lccccc}
\hline \hline & $M$ & $S D$ & 2 & 3 & 4 \\
\hline 1. Work demands & 4.24 & 0.91 & $.40^{* *}$ & -.05 & .07 \\
2. Depletion of self-regulatory resources & 3.37 & 1.11 & - & $-.40^{* *}$ & -.03 \\
3. Accommodation & 4.80 & 0.81 & & - & $.34^{*}$ \\
4. Dispositional self-control & 4.64 & 0.80 & & & - \\
\hline \hline
\end{tabular}

Note. $N=47$.

$* p<.05 . * * p<.01$.

of self-regulatory resources. Dispositional self-control was measured with 13 items of the Self-Control Scale (SCS; Tangney et al., 2004). An example item is: "I am good at resisting temptation" (Cronbach's $\alpha=.70$ ). Accommodation was measured with the 16-item Accommodation Scale (Rusbult et al., 1991), for example: "When my partner would say something really mean now, I would talk to my partner about what's going on, trying to work out a solution" (Cronbach's $\alpha=.73$ ). All items were measured on a 7-point scale $(1=$ totally disagree to $7=$ totally agree $)$, and we computed the means of the items of each scale.

\section{Results}

Means, standard deviations, and correlations of the study variables are presented in Table 1. Work demands were significantly related to depletion of self-regulatory resources, thereby meeting the primary prerequisite to test a moderated mediation effect (Preacher, Rucker, \& Hayes, 2007). We tested the moderated mediation hypothesis with a regression analysis using the SPSS macro PROCESS of Hayes (2013), which is designed to test moderated mediation. First, the depletion of self-regulatory resources (the mediator) was significantly predicted by work demands, $F(1$, $45)=8.74, b=.39, \quad S E=.13, p<.01$. Subsequently, accommodation was significantly predicted by depletion $(b=-.49, S E=.15$, $p<.01)$ and by the interaction between self-regulatory resources and dispositional self-control (Mediator $\times$ Moderator, $b=.36$, $S E=.18, p=.05), F(4,42)=5.36, p<.01$. In this regression, the main effects of work demands $(b=.16, S E=.14, p=.28)$ and dispositional self-control $(b=.22, S E=.14, p=.12)$ were not significant. The regression explained $34 \%$ of the variance in accommodation. The significant interaction effect supported the assumption of moderated mediation (Hayes, 2013). Given the significant interaction term, bootstrap analyses were conducted on the hypothesis that the conditional indirect effect equals zero at specific values (mean $\pm 1 S D$ ) of the moderator.

Bootstrapping is a statistical resampling method that estimates the parameters of a model and their standard errors strictly from the sample and computes more accurate confidence intervals than more commonly used methods, such as Baron and Kenny's (1986) causal steps strategy (Preacher \& Hayes, 2008). Preacher and Hayes (2004, 2008) state that the bootstrapping method circumvents power problems and that this method can be applied to small samples with more confidence than alternative methods. In support of Hypothesis 1, depletion of self-regulatory resources mediated the effect of work demands at low $(-1 S D)$ and mean levels of dispositional self-control but not when dispositional self-control was high $(+1 S D$; see Table 2).

An additional result of using the PROCESS macro is that we detected where the interaction effect was situated because the model needs to be specified to one of the several options of what a moderated mediation effect can look like (Hayes, 2013). Therefore, an additional finding is that the moderator effect of dispositional self-control was situated between the mediator (self-regulatory resources) and the dependent variable (accommodation). Other 
Table 2. Bootstrap analyses of conditional indirect effects (moderated mediation effects) of work demands on accommodation through self-regulatory resources (Study 1)

\begin{tabular}{lccrr}
\hline \hline & Indirect effect & SE & LLCI & ULCI \\
\hline $\mathrm{WD} \rightarrow \mathrm{DEP} \rightarrow$ ACC (low DSC, $-1 S D)$ & $-.35^{*}$ & .18 & -.80 & -.07 \\
$\mathrm{WD} \rightarrow \mathrm{DEP} \rightarrow$ ACC (mean DSC) & $-.20^{*}$ & .09 & -.44 & -.06 \\
$\mathrm{WD} \rightarrow \mathrm{DEP} \rightarrow \mathrm{ACC}($ high DSC,$+1 S D)$ & -.06 & .10 & -.29 & .14 \\
\hline \hline
\end{tabular}

Note. Bootstrap sample size $=5,000$ bootstrap resamples; $R^{2}=.34 ; \mathrm{WD}=$ work demands; $\mathrm{DEP}=$ depletion of self-regulatory resources; $\mathrm{ACC}=$ accommodation; $\mathrm{DSC}=$ dispositional self-control; $\mathrm{LLCI}=95 \%$ lower limit confidence interval; ULCI $=95 \%$ upper limit confidence interval.

$*$ Significant effect, $N=47$.

options of moderated mediation did not provide significant interaction effects.

\section{Discussion}

As expected, work demands were negatively related to accommodation via the self-reported depletion of self-regulatory resources. In line with our expectations, this spillover effect was only present for individuals with average or low levels of dispositional self-control. Consistent with Hypothesis 1, work demands were related to a decrease in self-regulatory resources, which were subsequently related to less accommodation toward the partner, especially for individuals high in dispositional self-control. The findings further suggest that individuals high in dispositional self-control can become depleted from their self-regulatory resources just like individuals low in dispositional self-control, but depletion does not relate to a decrease in accommodative tendencies toward their partner for those high in dispositional self-control.

\section{Study 2}

In Study 2, we aimed to further investigate how the depletion of self-regulatory resources after a workday is related to relationship behavior. We expected that psychological availability mediates the association between the depletion of self-regulatory resources and accommodation, but more strongly for individuals low in dispositional self-control compared to individuals high in dispositional self-control (i.e., a moderated mediation effect; Hypothesis 2). In order to attain a higher percentage of women than in Study 1, we decreased the work hour criterion in the second study to $12 \mathrm{hr}$ a week, which is the threshold to be counted as part of the labor force in The Netherlands (Mol, 2008). In addition, to ensure that individuals had recent work experiences, we included the criterion that individuals had to complete the questionnaire in the evening after a workday.

\section{Method}

\section{Participants and procedure}

We used the same procedure as in Study 1, except for the adjusted participation criteria and the completion of the questionnaire in the evening of a workday. We recruited 96 members of dual-earner families who had at least one child living at home to participate in this study. Gender was equally divided ( $48 \%$ was male; $52 \%$ was female); $81 \%$ of the sample was married, and the remaining $19 \%$ cohabitated. The average age of participants was 42.43 years $(S D=8.16$, range $=24-65$ years). Male respondents worked on average $38.52 \mathrm{hr}$ per week $(S D=7.80)$, and female respondents worked on average $26.74 \mathrm{hr}$ per week $(S D=7.62)$. Most participants were highly educated $(75 \%$ higher education or higher vocational education). Participants had on average 2.08 children $(S D=0.69)$ between 0 and 22 years old. The average age of the youngest child was $6.65(S D=5.12)$.

\section{Measures}

Similar to Study 1, respondents completed the questions on depletion of self-regulatory resources (Cronbach's $\alpha=.84$ ) 
Table 3. Means, standard deviations, and correlations of the study variables (Study 2)

\begin{tabular}{lccccc}
\hline \hline & $M$ & $S D$ & 2 & 3 & 4 \\
\hline 1. Depletion of self-regulatory resources & 3.35 & 1.04 & $-.47^{* *}$ & $-.20^{+}$ & $-.19^{+}$ \\
2. Psychological availability & 4.56 & 0.93 & - & $.41^{* *}$ & $.24^{* *}$ \\
3. Accommodation & 4.69 & 0.67 & & - & $.31^{* *}$ \\
4. Dispositional self-control & 4.70 & 0.85 & & & - \\
\hline \hline
\end{tabular}

Note. $N=96$.

${ }^{+} p<.10 . * * p<.01$.

and dispositional self-control (Cronbach's $\alpha=.77$ ) as well as accommodation (Cronbach's $\alpha=.71$ ) about the preceding workday. In addition, participants completed the Daily Psychological Availability Scale (Danner-Vlaardingerbroek et al., 2013). This scale consists of eight items measuring the accessibility of psychological resources to be used in the direction of the partner $(1=$ totally disagree, $7=$ totally agree). Example items are: "When I was with my partner at the end of this workday..." “... mentally, I was not 'fully there' for my partner" or “... my thoughts were completely focused on my partner." The scale had a good reliability coefficient (Cronbach's $\alpha=.77$ ). We computed the means of the items of each scale. A higher score represents more psychological availability for the partner. Because we decreased the work hour criterion, the weekly work hours varied more between participants compared to Study 1, especially for men $(S D=4.50$ in Study 1 and $S D=7.80$ in Study 2). We therefore controlled for weekly work hours in Study 2.

\section{Results}

Means, standard deviations, and correlations are presented in Table 3. Depletion of self-regulatory resources was significantly related to psychological availability (see Table 3), thereby meeting the primary prerequisite to test a moderated mediation effect (Preacher et al., 2007). We tested the moderated mediation hypothesis by conducting a regression analysis using the SPSS macro PROCESS of Hayes (2013). First, psychological availability (the mediator) was significantly predicted by depletion of self-regulatory resources $(b=-.48, S E=.09, p<.01)$. The control variable weekly work hours was not a significant predictor of psychological availability $(b=.06, S E=.09, p=.54), F(2$, $93)=13.50, p<.01, R^{2}=.23$. Subsequently, accommodation was significantly predicted by psychological availability $(b=.38, S E=.11$, $p<.01)$, dispositional self-control $(b=.20$, $S E=.09, p=.04)$, and by the interaction between psychological availability and dispositional self-control (Mediator $\times$ Moderator; $b=-.19, S E=.09, p=.04), F(4,91)=7,48$, $p<.01$. Depletion of self-regulatory resources and the control variable weekly work hours were not significant predictors of accommodation $(b=-.03, S E=.11, p=.76$ and $b=.12$, $S E=.09, p=.04$, respectively). The regression explained $26 \%$ of the variance in accommodation. The significant interaction effect supported the assumption of moderated mediation.

Given the significant interaction term, bootstrap analyses were conducted on the hypothesis that the conditional indirect effect equals zero at specific values (mean $\pm 1 S D$ ) of the moderator. Psychological availability mediated the effect of depletion of self-regulatory resources at low and mean levels ( $-1 S D$ and mean) but not at high levels of dispositional self-control $(+1 S D$; see Table 4). As expected, the negative association between depletion of self-regulatory resources and accommodation was mediated by a decrease in psychological availability. In line with our expectations and with Study 1 , this effect was only present for individuals with low or mean levels of dispositional self-control but not for individuals with high dispositional self-control. 
Table 4. Bootstrap analyses of conditional indirect effects (moderated mediation effects) of self-regulatory resources on accommodation through psychological availability (Study 2)

\begin{tabular}{lccrr}
\hline \hline Conditional indirect effects & Indirect effect & SE & LLCI & ULCI \\
\hline $\mathrm{DEP} \rightarrow \mathrm{PA} \rightarrow$ ACC (low DSC, -1 SD) & $-.27^{*}$ & .10 & -.49 & -.11 \\
$\mathrm{DEP} \rightarrow \mathrm{PA} \rightarrow$ ACC (mean DSC) & $-.18^{*}$ & .07 & -.36 & -.07 \\
$\mathrm{DEP} \rightarrow \mathrm{PA} \rightarrow$ ACC (high DSC,$+1 S D)$ & -.10 & .07 & -.27 & .01 \\
\hline \hline
\end{tabular}

Note. Bootstrap sample size $=5,000$ bootstrap resamples; $R^{2}=.25 ; \mathrm{DEP}=$ depletion of self-regulatory resources; $\mathrm{PA}=$ psychological availability $\mathrm{ACC}=$ accommodation; $\mathrm{DSC}=$ dispositional self-control LLCI $=95 \%$ lower limit confidence interval; ULCI $=95 \%$ upper limit confidence interval.

$*$ Significant effect, $N=96$.

An additional result is that we detected where the interaction effect was situated because we used the macro of Hayes (2013). Similar to Study 1, the interaction effect was situated between the mediator (psychological availability) and the dependent variable accommodation. Other options of moderated mediation did not provide significant interaction effects. This suggests that the depletion of self-regulatory resources is related to a decrease in psychological availability for individuals high in dispositional self-control, just like individuals low in dispositional self-control. However, for those high in dispositional self-control, this decrease in psychological availability was not related to a decrease in accommodative tendencies toward the partner.

\section{Discussion}

Study 2 showed that individuals with average or low levels of dispositional self-control who are depleted from work accommodate less toward their partner via decreased psychological availability for their partner, whereas for those high in dispositional self-control, a decrease in psychological availability for the partner was not related to less accommodation. These results add to Study 1, which showed that work demands were related in accommodation via depletion of resources, but only for individuals with low and mean levels of dispositional self-control. The findings of Study 2 explain how work demands spill over into the relationship: Work can deplete individuals, and depleted individuals have more difficulties in directing their attention on their partner, which explains why they have difficulties in accommodating. This, however, does not apply to individuals with high dispositional self-control as they accommodated regardless of their depletion and lowered psychological availability.

Several limitations to the two preceding studies require mention. First, accommodative behavior was measured as hypothetical behavior. Respondents had to imagine an outlined situation and report on how they would react to this situation in their current state, which can be less accurate than reporting real behavior. Second, the data were correlational and partly retrospective; work demands, depletion of self-regulatory resources, and psychological availability at the end of the workday were assessed at the same time as accommodative tendencies. Retrospective accounts of behavior are less accurate than concurrent reports of behavior, and because the data were all measured at one point in time, no causal inferences can be made about the relationships that were found.

\section{Study 3}

We conducted Study 3 to overcome the limitations in the Studies 1 and 2. We aimed to improve the generalizability of the results by manipulating individuals' psychological availability for their partner after work through a writing assignment. In addition, we used a self-report behavioral measure of relationship behavior instead of the hypothetical measure that we used in Studies 1 and 2. Real-life accommodation is difficult to measure because it is a reaction to the destructive behavior of 
the partner. Accommodation is thus dependent on whether the partner has shown destructive behavior during the evening on the day of participation. Because we preferred to measure relationship behavior in a natural setting, we chose to assess general positive relationship behavior in Study 3. To further improve the methodology compared to Studies 1 and 2, we assessed depletion of self-regulatory resources and conducted the writing assignment directly after work and assessed positive relationship behavior at the end of the evening.

We aimed to manipulate psychological availability by increasing the resources and directing these resources at the partner. We used the "gratitude writing assignment" that asks participants to write down three recent situations in which their partner had been kind to them and to explain why they were grateful for their partner. The gratitude writing assignment was derived from a combination of two existing positive interventions: "gratitude visit" and "three good things in life" (Seligman, Steen, Park, \& Peterson, 2005). Because gratitude is a positive emotion, it has the potential to increase the resources for the partner (e.g., Fredrickson, Mancuso, Branigan, \& Tugade, 2000; Tice, Baumeister, Shmueli, \& Muraven, 2007). In addition, gratitude can be characterized as "other directed" (Emmons \& McCullough, 2003; Tsang, 2006). Because of the external focus of this emotion, gratitude stimulates sensitivity and concern for others (Kubacka, Finkenauer, Rusbult, \& Keijsers, 2011; McCullough, Emmons, \& Tsang, 2002). We therefore argue that the induction of gratitude has the potential to increase an individuals' psychological availability for the partner by increasing the individual's resources and directing them at the partner.

By increasing psychological availability for the partner with the gratitude writing task, we expected that individuals would show more positive relationship behavior than individuals whose psychological availability was not increased. In line with the previous studies, we expected this effect to be stronger for individuals low in dispositional self-control compared to individuals high in dispositional self-control (Hypothesis 3).

\section{Method}

\section{Participants and procedure}

Participants were 62 members of dual-earner families, mainly women (57) and a few men (5). Participants had at least one child living at home and worked for at least $12 \mathrm{hr}$ per week. They were recruited from a subject pool from a larger study among dual-earner families. The reason why mainly women participated was that the majority of the men in the other study had indicated that they were not willing to participate in future studies. Participants received a personal link for an online questionnaire 1 $\mathrm{hr}$ before the end of their workday and another one during the evening. This way, the two questionnaires of participants could be linked, and it was ensured that participants filled out the questionnaires on the right day at the right time. Participants received a small gift (i.e., a magazine) after filling out both questionnaires. The average age of participants was 42.08 years $(S D=5.63$, range $=29-55$ years $)$, and participants worked on average $29.11 \mathrm{hr}$ per week $(S D=8.37)$. The average relationship duration of participants was 17.67 years $(S D=6.08)$. Participants had on average 2.44 children $(S D=0.89)$ aged between 0 and 26 years. Most participants were higher educated (77\% higher education or higher vocational education).

\section{Measures}

To assess depletion of self-regulatory resources, respondents completed the Concurrent Depletion Scale (Finkel \& Campbell, 2001) at the end of a workday before going home (Cronbach's $\alpha=.76$ ). Half of the participants also completed the gratitude writing assignment to increase psychological availability (the experimental group), while the other half did not (the control group). In the evening, all participants completed a four-item subscale that assessed daily positive relationship behavior (Gable, Reis, \& Downey, 2003). Example questions are: "I was physically affectionate toward my partner" and "I told my partner I loved him/her" (Cronbach's $\alpha=.76$ ). In the evening, all participants also reported on dispositional self-control with the SCS 
Table 5. Means, standard deviations, and correlations of the study variables (Study 3)

\begin{tabular}{lcccc}
\hline \hline & $M$ & $S D$ & 2 & 3 \\
\hline 1. Depletion of self-regulatory resources & 3.76 & 0.82 & -.14 & $.27^{*}$ \\
2. Positive relationship behavior & 4.17 & 1.18 & - & $-.24^{+}$ \\
3. Dispositional self-control & 3.70 & 0.89 & & - \\
\hline \hline
\end{tabular}

Note. $N=62$.

${ }^{+} p<.10 . * p<.05$.

Table 6. Differences between groups on positive relationship behavior at different values of dispositional self-control, controlled for depletion of self-regulatory resources (Study 3)

\begin{tabular}{lccccc}
\hline \hline $\begin{array}{l}\text { Dispositional } \\
\text { self-control }\end{array}$ & $\begin{array}{c}\text { Experimental } \\
\text { group } M(S E)\end{array}$ & $\begin{array}{c}\text { Control } \\
\text { group } M(S E)\end{array}$ & $F(d f)$ & $p$ & Partial $\eta^{2}$ \\
\hline Low $(-1 S D)$ & $4.31(.25)$ & $3.18(.34)$ & $F(1,57)=7.03$ & .01 & .11 \\
Mean $(0 S D)$ & $4.30(.20)$ & $3.86(.21)$ & $F(1,57)=2.28$ & .14 & .04 \\
High $(+1 S D)$ & $4.29(.32)$ & $4.54(.27)$ & $F(1,57)=0.35$ & .56 & .01 \\
\hline \hline
\end{tabular}

Note. $N=62$.

(Tangney et al., 2004; Cronbach's $\alpha=.80$ ). We computed the means of the items of each scale.

\section{Results and discussion}

Means, standard deviations, and correlations between the study variables are presented in Table 5. Bivariate analyses of variance were conducted to test whether the experimental group and the control group differed on daily positive relationship behavior while controlling for the depletion of self-regulatory resources. Main effects of group, dispositional self-control, and depletion of self-regulatory resources were entered into the analyses, as well as the interaction between group and dispositional self-control. As expected, results showed a significant interaction effect between group and dispositional self-control, $F(1$, $57)=5.06, p=.03$, in addition to a significant main effect of dispositional self-control, $F(1,57)=4.84, p=.03$. The other effects were not significant. Without taking depletion of self-regulatory resources into account, the interaction was marginally significant, $F(1,57)=3.43, p=.06$. This implies that it matters to take the depletion of self-regulatory resources by work into account.

To interpret the significant interaction effect, group differences of positive relationship behavior were calculated at different values of dispositional self-control while controlling for depletion of self-regulatory resources. As predicted by Hypothesis 3, individuals low in dispositional self-control who were assigned to the experimental group reported more positive relationship behavior than low dispositional self-control individuals from the control group (medium effect size). For individuals with mean and high values of dispositional self-control, the experimental group and the control group did not differ in the reported positive relationship behavior (see Table 6). Hence, as expected, individuals who did the gratitude writing task after work showed more positive relationship behavior than individuals who did not, but only when they had low dispositional self-control.

\section{General Discussion}

The first purpose of the present research was to illuminate our understanding of how and for whom work experiences spill over into relationship interactions. Building on earlier work-family spillover research and using principles of interdependence theory, we hypothesized that the association between work experiences and relationship behavior was mediated by differences in 
temporal self-control resources and subsequently by psychological availability for the partner. In addition, we hypothesized that this would be the case for individuals low in dispositional self-control in particular. Consistent with our hypotheses, Study 1 revealed that work demands were negatively related to accommodation via the depletion of self-regulatory resources, but only for individuals with average or low levels of dispositional self-control. Furthermore, Study 2 revealed that psychological availability mediated the negative association between depletion of self-regulatory resources and accommodation, again only for individuals with average or low levels of dispositional self-control. Finally, Study 3 showed that, dependent on the level of dispositional self-control, participants who conducted a writing assignment that was aimed at increasing psychological availability for the partner reported more positive relationship behavior.

The present research extends earlier work on work-family spillover by providing more insight into how and for whom work experiences spill over into relationship behavior. First, the current research further unravels the how question, by including work experiences, self-regulatory depletion, psychological availability, and subsequent relationship behavior. In the previous literature, relationship behavior was predicted by work experiences like workload (Hughes \& Galinsky, 1994) via workday residuals like mood (Story \& Repetti, 2006). A recent study showed that psychological availability mediated the association between workday residuals and relationship behavior (Danner-Vlaardingerbroek et al., 2013). This study showed that experiences during the workday (i.e., work demands) were related to residuals of the workday as assessed by the depletion of self-regulatory resources of the individual (Study 1). Subsequently, depletion was related to a decreased psychological availability, which was, in turn, related to a decrease of positive relationship behavior (Studies 2 and 3). In sum, findings of the current study suggest that by the depletion of self-regulatory resources and thereby diminished psychological availability for the partner, the work domain can hinder the ability to maintain positive daily interactions within close relationships.

Second, the present research extended previous research by investigating individual differences in the work-family spillover process. Whether work demands spill over into relationship behavior depends on dispositional self-control. All three studies indicated that individuals with low dispositional self-control are more vulnerable to work-relationship spillover than individuals characterized by high dispositional self-control. Although there are a number of studies that show the advantages of dispositional self-control in many forms of behavior (for an overview, see Baumeister \& Vohs, 2007), this is the first study to our knowledge that investigates dispositional self-control as an individual difference variable in the work-family spillover context. Moreover, the results of Study 3 imply that the induction of feelings of gratitude for the partner helps individuals with a low dispositional self-control to show positive relationship behavior.

In addition to the hypothesized findings, we found that even though individuals high in dispositional self-control become depleted after a tough workday and experience a decrease in their psychological availability for the partner, they are still able to exert positive relationship behavior. A possible explanation for this finding can be found in research on automatic behavior. Research on the self-regulatory strength model generally assumes that behaviors that are more effortful also consume more self-regulatory resources than automatic behaviors (Baumeister et al., 2007). Because habits appear relatively automatic (Baumeister \& Alquist, 2009), people who are high in dispositional self-control are probably good at automatizing positive or healthy behavior into habits (de Ridder, Lensvelt-Mulders, Finkenauer, Stok, \& Baumeister, 2012). In the context of relationship behavior, this could imply that individuals high in dispositional self-control have habituated positive interpersonal behaviors, which should feature in a lower cost of self-regulatory resources to perform these positive relationship behaviors. This could explain why individuals high in dispositional self-control can exhibit more 
positive relationship behavior in spite of the depletion of self-regulatory resources and diminished psychological availability for the partner.

Although the results of this study provide interesting theoretical insights, several limitations qualify our conclusions. First, the sample sizes of the three studies were rather small; the results should therefore be replicated by studies with larger sample sizes to increase the credibility of the results. Second, all three studies are based on self-reports of partner-relationship behavior. Results of this study would be strengthened when replicated, for example by partner reports or by independent observations of relationship behavior. Third, all three studies were conducted using Dutch convenience samples, resulting in mainly highly educated participants, relatively many of which held a part-time job. Because working part-time is more common in The Netherlands than in other Western nations, additional research in other national contexts is needed to further establish the robustness of the present findings. We do, however, think that larger effects might be obtained for samples with more work hours and subsequent higher depletion of self-regulatory resources. In that sense, this study can be regarded as a conservative test of our hypothesis. Fourth, the distribution of males and females in the samples varied across the three studies. However, that similar results for dispositional self-control were found in all three samples suggests that these results are robust across gender as males were overrepresented in the first study, and females were overrepresented in the third study. Finally, a limitation of the third study is that there was no second control condition with an alternative assignment (Orne, 2009). We cannot rule out that the gratitude writing assignment influenced the relationship behavior reports because participants took some time to think about something other than work after the workday.

This study raises interesting questions for future research. It is important to extend the findings of this study with longitudinal research. When the induction of feelings of gratitude for the partner indeed results in improvements of daily partner interactions, it would be interesting to construct an easy-to-apply intervention and examine whether such an intervention positively affects relationship duration in the long run. Also, our samples consisted of Dutch dual-earner highly educated families. It would be interesting to extend the results to other types of families, such as families in which only one of the partners has a paid job, families with a lower social economic status, and families in other countries.

In addition to expanding theoretical insights, our research has implications for practitioners who work in work-family contexts or assist partner relationships. Findings of this study showed that possessing high dispositional self-control can help employees to restrain negative spillover from work from affecting their relationship behavior at home. Findings of this study further showed that the induction of gratitude, which can easily be applied, might help individuals who are not equipped with this helpful personality trait to overcome the depleting effects of work demands, resulting in more positive relationship behavior. Furthermore, although dispositional self-control is a relatively stable personality trait, it can be trained (Baumeister \& Alquist, 2009), which makes low self-control individuals less vulnerable to fluctuations in temporal levels of depletion or psychological availability for their partner. To conclude, this study shows that the negative impact of a demanding workday on partner relationships can be prevented by either having good self-control qualities or by the induction of gratitude for the partner.

\section{References}

Bakker, A. B., Demerouti, E., \& Burke, R. (2009). Workaholism and relationship quality: A spillover-crossover perspective. Journal of Occupational Health Psychology, 14, 23-33. doi:10.1037/a0013290

Bakker, A. B., \& Geurts, S. A. E. (2004). Toward a dual-process model of work-home interference. Work and Occupations, 31, 345-366. doi:10.1177/073088 8494021004010

Baron, R. M., \& Kenny, D. A. (1986). The moderator-mediator variable distinction in social psychological research: Conceptual, strategic, and statistical considerations. Journal of Personality and Social Psychology, 51, 1173-1182. doi:10.1037/00223514.51.6.1173 
Baumeister, R. F., \& Alquist, J. L. (2009). Is there a downside to good self-control? Self and Identity, 8, 115-130. doi:10.1080/15298860802501474

Baumeister, R. F., Bratslavsky, E., Finkenauer, C., \& Vohs, K. D. (2001). Bad is stronger than good. Review of General Psychology, 5, 323-370. doi:10.1037// 1089-2680.5.4.323

Baumeister, R. F., Gailliot, M., DeWall, C. N., \& Oaten, M. (2006). Self-regulation and personality: How interventions increase regulatory success, and how depletion moderates the effects of traits on behavior. Journal of Personality, 74, 1773-1802. doi:10.1111/j. 1467-6494.2006.00428.x

Baumeister, R. F., \& Heatherton, T. F. (1996). Self-regulation failure: An overview. Psychological Inquiry, 7, 1-15. doi:10.1207/s15327965pli0701_1

Baumeister, R. F., \& Vohs, K. D. (2007). Self-regulation, ego depletion, and motivation. Social and Personality Psychology Compass, 1, 1-14. doi:10.1111/j.17519004.2007.00001.x

Baumeister, R. F., Vohs, K. D., \& Tice, D. M. (2007). The strength model of self-control. Current Directions in Psychological Science, 16, 351-355. doi:10.1111/j. 1467-8721.2007.00534.x

Bianchi, S. M., Robinson, J. P., \& Milkie, M. A. (2006). Changing rhythms of American family life. New York, NY: Russell Sage Foundation.

Danner-Vlaardingerbroek, G., Kluwer, E. S., van Steenbergen, E. F., \& van der Lippe, T. (2013). Knock, knock, anybody home? Psychological availability as link between work and relationship. Personal Relationships, 20, 52-68. doi:10.1111/j.1475-6811.2012. 01396.x

De Ridder, D. T. D., Lensvelt-Mulders, G., Finkenauer, C., Stok, F. M., \& Baumeister, R. F. (2012). Taking stock of self-control: A meta-analysis of how trait self-control relates to a wide range of behaviors. Personality and Social Psychology Review, 16, 76-99. doi:10.1177/1088868311418749

Eby, L. T., Casper, W. J., Lockwood, A., Bordeaux, C., $\&$ Brinley, A. (2005). Work and family research in IO/OB: Content analysis and review of the literature (1980-2002). Journal of Vocational Behavior, 66, 124-197. doi:10.1016/j.jvb.2003.11.003

Emmons, R. A., \& McCullough, M. E. (2003). Counting blessings versus burdens: An experimental investigation of gratitude and subjective well-being in daily life. Journal of Personality and Social Psychology, 84, 377-389. doi:10.1037/0022-3514.84.2.377

Finkel, E. J., \& Campbell, W. K. (2001). Self-control and accommodation in close relationships: An interdependence analysis. Journal of Personality and Social Psychology, 81, 263-277. doi:10.1037/0022-3514. 81.2.263

Fredrickson, B. L., Mancuso, R. A., Branigan, C., \& Tugade, M. M. (2000). The undoing effect of positive emotions. Motivation and Emotion, 24, 237-258. doi:10.1023/A:1010796329158

Gable, S. L., Reis, H. T., \& Downey, G. (2003). He said, she said: A quasi-signal detection analysis of daily interactions between close relationship partners. Psychological Science, 14, 100-105. doi:10.1111/14679280.t01-1-01426

Green, J. D., Sedikides, C., Saltzberg, J. A., Wood, J. V., \& Forzano, L. A. B. (2010). Happy mood decreases self-focused attention. British Journal of Social Psychology, 42, 147-157. doi:10.1348/0144666037632 76171

Greenhaus, J. H., \& Beutell, N. J. (1985). Sources of conflict between work and family roles. The Academy of Management Review, 10, 76-88.

Hayes, A. F. (2013). An introduction to mediation, moderation, and conditional process analysis: A regression-based approach. New York, NY: Guilford Press.

Hughes, D., \& Galinsky, E. (1994). Work experiences and marital interactions: Elaborating the complexity of work. Journal of Organizational Behavior, 15, 423-438. doi:10.1002/job.4030150507

Kelley, H. H., \& Thibaut, J. W. (1978). Interpersonal relations: A theory of interdepence. New York, NY: Wiley.

Kubacka, K. E., Finkenauer, C., Rusbult, C. E., \& Keijsers, L. (2011). Maintaining close relationships: Gratitude as a motivator and a detector of maintenance behavior. Personality and Social Psychology Bulletin, 37, 1362-1375. doi:10.1177/0146167211412196

McCullough, M. E., Emmons, R. A., \& Tsang, J. (2002). The grateful disposition: A conceptual and empirical topography. Journal of Personality and Social Psychology, 82, 112-127. doi:10.1037/0022-3514.82.1.112

Merens, A., Hartgers, M., \& van den Brakel, M. (2012). Emancipatiemonitor 2012 [Emancipation monitor 2012]. The Hague, Netherlands: Netherlands Institute for Social Research/Statistics Netherlands.

Miyake, A., Friedman, N. P., Emerson, M. J., Witzki, A. H., Howerter, A., \& Wager, T. D. (2000). The unity and diversity of executive functions and their contributions to complex "frontal lobe" tasks: A latent variable analysis. Cognitive Psychology, 41, 49-100. doi:10.1006/cogp.1999.0734

Mol, M. (2008). Levensfasen van kinderen en het arbeidspatroon van ouders [Life stages of children and the working patterns of parents]. Sociaaleconomische trends [Socio-Economic Trends], 1, 11-16.

Monsell, S. (2003). Task switching. Trends in Cognitive Sciences, 7, 134-140. doi:10.1016/S13646613(03)00028-7

Orne, M. T. (2009). Demand characteristics and the concept of quasi-controls. In R. Rosenthal \& R. L. Rosnow (Eds.), Artifacts in behavioral research: Robert Rosenthal and Ralph L. Rosnow's Classic Books (pp. 110-137). Oxford, England: Oxford University Press.

Piotrkowsky, C. S. (1979). Work and the family system: A naturalistic study of working-class and lower idle-class families. New York, NY: Free Press.

Preacher, K. J., \& Hayes, A. F. (2004). SPSS and SAS procedures for estimating indirect effects in simple mediation models. Behavior Research Methods, 36, 717-731. 
Preacher, K. J., \& Hayes, A. F. (2008). Asymptotic and resampling strategies for assessing and comparing indirect effects in multiple mediator models. Behavior Research Methods, 40, 879-891.

Preacher, K. J., Rucker, D. D., \& Hayes, A. F. (2007). Addressing moderated mediation hypotheses: Theory, methods, and prescriptions. Multivariate Behavioral Research, 42, 185-227. doi:10.1080/002731707 01341316

Repetti, R. L. (1993). Short-term effects of occupational stressors on daily mood and health complaints. Health Psychology, 12, 125-131. doi:10.1037/02786133.12.2.125

Rogers, S. J., \& May, D. C. (2003). Spillover between marital quality and job satisfaction: Long-term patterns and gender differences. Journal of Marriage and Family, 65, 482-495. doi:10.1111/j.1741-3737.2003.00482.x

Rusbult, C. E., \& van Lange, P. A. M. (1996). Interdependence processes. In E. T. Higgins \& A. Kruglanski (Eds.), Social psychology: Handbook of basic mechanisms and processes (pp. 564-596). New York, NY: Guilford Press.

Rusbult, C. E., Verette, J., Whitney, G. A., Slovik, L. F., \& Lipkus, I. (1991). Accommodation processes in close relationships: Theory and preliminary empirical evidence. Journal of Personality and Social Psychology, 60, 53-78. doi:10.1037/0278-6133.12.2.125

Seligman, M. E. P., Steen, T. A., Park, N., \& Peterson, C. (2005). Positive psychology progress: Empirical validation of interventions. American Psychologist, 60, 410-421. doi:10.1037/0003-066X.60.5.410

Song, Z., Foo, M. D., \& Uy, M. A. (2008). Mood spillover and crossover among dual-earner couples: A cell phone event sampling study. Journal of Applied Psychology, 93, 443-452. doi:10.1037/0021-9010.93.2.443
Stafford, L., \& Canary, D. J. (1991). Maintenance strategies and romantic relationship type, gender and relational characteristics. Journal of Social and Personal Relationships, 8, 217-242. doi:10.1177/026540 7591082004

Story, L. B., \& Repetti, R. (2006). Daily occupational stressors and marital behavior. Journal of Family Psychology, 20, 690-700. doi:10.1037/08933200.20.4.690

Tangney, J. P., Baumeister, R. F., \& Boone, A. L. (2004). High self-control predicts good adjustment, less pathology, better grades, and interpersonal success. Journal of Personality, 72, 271-324. doi:10.1111/j. 0022-3506.2004.00263.x

Tice, D. M., Baumeister, R. F., Shmueli, D., \& Muraven, M. (2007). Restoring the self: Positive affect helps improve self-regulation following ego depletion. Journal of Experimental Social Psychology, 43, 379-384. doi:10.1016/j.jesp.2006.05.007

Tsang, J. A. (2006). Gratitude and prosocial behaviour: An experimental test of gratitude. Cognition and Emotion, 20, 138-148. doi:10.1080/02699930500172341

Vohs, K. D., Finkenauer, C., \& Baumeister, R. F. (2011). The sum of friends' and lovers' self-control scores predicts relationship quality. Social Psychological and Personality Science, 2, 138-145. doi:10.1177/1948550610385710

Williams, K. J., \& Alliger, G. M. (1994). Role stressors, mood spillover, and perceptions of work-family conflict in employed parents. The Academy of Management Journal, 37, 837-868. doi:10.2307/256602

Yovetich, N. A., \& Rusbult, C. E. (1994). Accommodative behavior in close relationships: Exploring transformation of motivation. Journal of Experimental Social Psychology, 30, 138-164. doi:10.1006/jesp.1994.1007 